\title{
Nrf2 as a Key Player of Redox Regulation in Cardiovascular Diseases
}

\author{
M. BARANČÍIK ${ }^{1}$, L. GREŠOVÁ ${ }^{2}$, M. BARTEKOVÁ ${ }^{1,3}$, I. DOVINOVÁ ${ }^{2}$ \\ ${ }^{1}$ Institute for Heart Research, Slovak Academy of Sciences, Bratislava, Slovak Republic, ${ }^{2}$ Institute \\ of Normal and Pathological Physiology, Slovak Academy of Sciences, Bratislava, Slovak Republic, \\ ${ }^{3}$ Institute of Physiology, Faculty of Medicine, Comenius University in Bratislava, Slovak Republic
}

Received June 10, 2016

Accepted June 24, 2016

\begin{abstract}
Summary
The oxidative stress plays an important role in the development of cardiovascular diseases (CVD). In CVD progression an aberrant redox regulation was observed. In this regulation levels of reactive oxygen species (ROS) play an important role in cellular signaling, where Nrf2 is the key regulator of redox homeostasis. Keap1-Nrf2-ARE system regulates a great set of detoxificant and antioxidant enzymes in cells after ROS and electrophiles exposure. In this review we focus on radical-generating systems in cardiovascular system as well as on Nrf2 as a target against oxidative stress and a key player of redox regulation in cardiovascular diseases. We also summarize the current knowledge about the role of Nrf2 in pathophysiology of several CVD (hypertension, cardiac hypertrophy, cardiomyopathies) as well as in cardioprotection against myocardial ischemia/ reperfusion injury.
\end{abstract}

\section{Key words}

Nrf2 pathway - Cardiovascular diseases - Oxidative stress • Radical signaling • Antioxidant response

\section{Corresponding author}

M. Barančík, Institute for Heart Research, Slovak Academy of Sciences, Dúbravská cesta 9, P.O.Box 104, 84005 Bratislava, Slovakia. E-mail: Miroslav.Barancik@savba.sk

\section{Introduction}

Cardiovascular diseases (CVD) belong to the most serious medical problems and represent a major cause of health complications and morbidity in modern society. The common feature of all risk factors of CVD is imbalance between pro- and anti-oxidative factors in the organism with an increased production of reactive oxygen species (ROS) and reactive nitrogen species (RNS). ROS and RNS are key players in normal cardiovascular physiology and signaling, but their increased levels lead to cellular injury and death (necrosis or apoptosis) through direct effects (lipid peroxidation) or indirect effects (activation of the redox signaling pathways). Cellular stress response or heat shock response are ancient and highly conserved cytoprotective mechanisms, which can be regulated through transcriptional, translational and post-translational levels. Cellular stress response represents modulation of endogenous cellular defense mechanisms using Vitagene system (Dattilo et al. 2015). This mechanism represents cytoprotective vitagenes involved in antioxidant defense, which are primary activated through the nuclear factor erythroid 2-related factor (Nrf2)-antioxidant response element (ARE) system (Carmona-Ramírez et al. 2013). The endogenous cellular modulation represents an innovative approach to therapeutic intervention in diseases causing chronic tissue damage, such as in neurodegeneration or cardiovascular diseases (Calabrese et al. 2012, Majzunová et al. 2013).

Pharmacological modulation of cellular stress response pathways has emerging implications for the treatment of human diseases. A critical key to successful medical intervention is getting the dose right. Hormesis is dose-response phenomenon, characterized by a low dose stimulation and a high dose inhibition, and represents an inverted U-shaped dose, J- or U-shaped dose response. This concept has been primary applicated to the field of 
neuroprotection and its mechanistic foundations (Calabrese et al. 2010), where regulation of the redox status through the Vitagene system has been suggested. This Vitagene system includes heat shock protein (Hsp) family such as Hsp 72, heme oxygenase-1 (HO-1), sirtuins, as well as thioredoxin/thioredoxin reductase. The activation of this system takes very important effects on CVD protection or neuroprotection (Cornelius et al. 2013, Dattilo et al. 2015).

The oxidative stress and increased production of ROS and RNS play an important role in the development of CVD such as hypertension, heart failure, atherosclerosis, diabetes, and cardiac hypertrophy (Giordano 2005, Konradi et al. 2015, Montezano et al. 2015), as well as during ageing (Tribulova et al. 2015). Major sources of myocardial ROS production include NADPH oxidases (NOX), xanthine oxidase (XO), uncoupled nitric oxide synthase (NOS), and mitochondria (Dikalov 2011, Dikalov and Ungvari 2013). A key role in orchestrating cellular antioxidant defenses and in maintaining redox homeostasis plays the pathway of redox-sensitive nuclear transcription factor Nrf2 (Papp et al. 2012, Huang et al. 2015). Nrf2-driven antioxidant defense mechanisms play a critical role in the induction of endogenous antioxidant enzymes acting against oxidative damage in a variety of cardiovascular diseases (Erkens et al. 2015).

In this review we focus on Nrf2-ARE pathway as a target against oxidative stress and a key player of redox regulation in cardiovascular diseases. We address radical-generating systems in cardiovascular system and mechanisms involved in control and regulation of $\mathrm{Nrf} 2$. Finally, we summarize the current knowledge about the role of $\mathrm{Nrf} 2$ in hypertension, cardiac hypertrophy, cardiomyopathies as well as in cardioprotection against myocardial ischemia/reperfusion injury.

\section{Radical-generating systems in cardiovascular disorders}

Cells or tissues are in a stable state if the rates of ROS and RNS production and scavenging capacity are essentially constant and in balance. Increased and cumulative formation of ROS and RNS induce oxidative stress which leads to a cellular redox imbalance, and this may be linked with various disease states of an organism such as development of hypertension. A large amount of evidence supports the role of vascular wall as a major source of reactive oxygen species. It has been shown that in cells several ROS sources such as NOX, XO, uncoupled NOS, mitochondrial electron transport chain (ETC) are functional. It was also found that activation of one ROS system can lead to activation of another one and this situation has been described as theory of ,kindling and bonfire" radicals (Harrison et al. 2010), which obtain also reciprocal feedback (Majzunova et al. 2013). The main ROS sources are NOX and mitochondrial ETC and have been studied in several experimental works (Dikalov 2011, Dikalov and Ungvari 2013). To the possible crosstalk of NOX and mitochondrial ETC point data showing stimulation of superoxide production in mitochondria after angiotensin II (AngII)-induced NADPH oxidase activation in endothelial cells (Dikalov et al. 2014). AngII stimulated NOX2 through angiotensin II receptor type 1 (AT1R), which is connected with G-protein and induced activation of proteinkinase C (PKC) and Src-kinase pathway. Overproduction of superoxide through NOX activates redox-sensitive mitochondrial PKC- $\varepsilon$ in mitochondia. PKC- $\varepsilon$ phosphorylates and activates mitochondrial ATP-dependent $\mathrm{K}^{+}$channels, that leads to $\mathrm{K}^{+}$influx, alkalization of matrix, mitochondria swelling, uncoupling of ETC and superoxide production (Dikalov and Ungvari 2013). Another way of ROS production in mitochondria can be realized through Src-redox sensitive kinase which is activated in consequence of increased levels of $\mathrm{H}_{2} \mathrm{O}_{2}$ produced by manganese superoxide dismutase (MnSOD). During stimulation of AngII through AT2 receptor localized in inner mitochondrial membrane, nitric oxide (NO) can react with superoxide leading to the production of the high reactive peroxynitrite $\left(\mathrm{ONOO}^{-}\right)$that can inactivate MnSOD and depress the dismutation of superoxide (Dikalov and Ungvari 2013).

\section{Nrf2 as a transcription factor involved in redox-sensitive signaling and antioxidant response}

Recent findings demonstrate that in the cardiovascular system of healthy animals in response to increased production of ROS and electrophiles, adaptive mechanisms are invoked that involve induction of Nrf2-driven antioxidant defense mechanisms. Several studies have demonstrated that loss and/or dysregulation of Nrf2 are often linked with various diseases (Erkens et al. 2015). Nrf2 is a transcription factor that plays a key role in regulation of intracellular redox signaling (Papp et al. 2012, Huang et al. 2015). Its effects are realized through the regulation of expression of several endogenous antioxidants and detoxification enzymes of 
phase II. Under normal conditions, Nrf2 is inhibited by Kelch-like ECH-associated protein 1 (Keap1). When cells are exposed to cellular stress, like ROS, the cysteine residues of Keap1 are modified by oxidative/electrophilic molecules. As a result of conformational changes of Keap1, the Cullin3/Rbx1-dependent polyubiquitination of Nrf2 assisted by Keap1 is blocked, Nrf2 escapes Keap1-mediated repression, and rapidly translocated into the nucleus (Buendia et al. 2016). In the nucleus forms Nrf2 heterodimerizes with small MAF or Jun proteins and the complex binds to a cis-acting element present in the promoter of its target genes, called ARE. The activation of ARE is followed by an activation of endogenous antioxidant response. These effects are realized above all during acute stress. By prolonged stress, Nrf2 is partially deactivated. In the Figure 1, activation and deactivation effects of different kinases are shown. Nrf2 activation is under control of regulation mediated by phosphatidylinositol-3-kinase (PI3K)/Akt,
PKC, and mitogen-activated protein kinases (MAPKs) (Kang et al. 2002, Numazawa et al. 2003, Sun et al. 2009). The effects of Akt kinase are associated with modulation of glycogen synthase kinase-3 $\beta$ (GSK-3 $\beta$ ). This enzyme is phosphorylated by Akt kinase and it has been found that can directly phosphorylate Nrf2 (Rada et al. 2011). GSK-3 $\beta$ can promote Nrf2 translocation from nucleus through the Fyn kinase activation and lead to deactivation of Nrf2 in the nucleus (Jain and Jaiswal 2008). Under normal conditions Bach1 (BTB and CNC homology 1) forms a heterodimer with small Maf protein and thereby suppress Nrf2 activation (Sun et al. 2004). Nrf2 activity is also regulated at post-transcriptional level by miRNA (Zhang et al. 2015). It has been demonstrated that the ectopic expression of miR-27a, miR-142-5p, miR-144, and miR-153 can affect the nucleo-cytoplasmic level of Nrf2 protein in a Keap1-independent manner (Narasimhan et al. 2012).
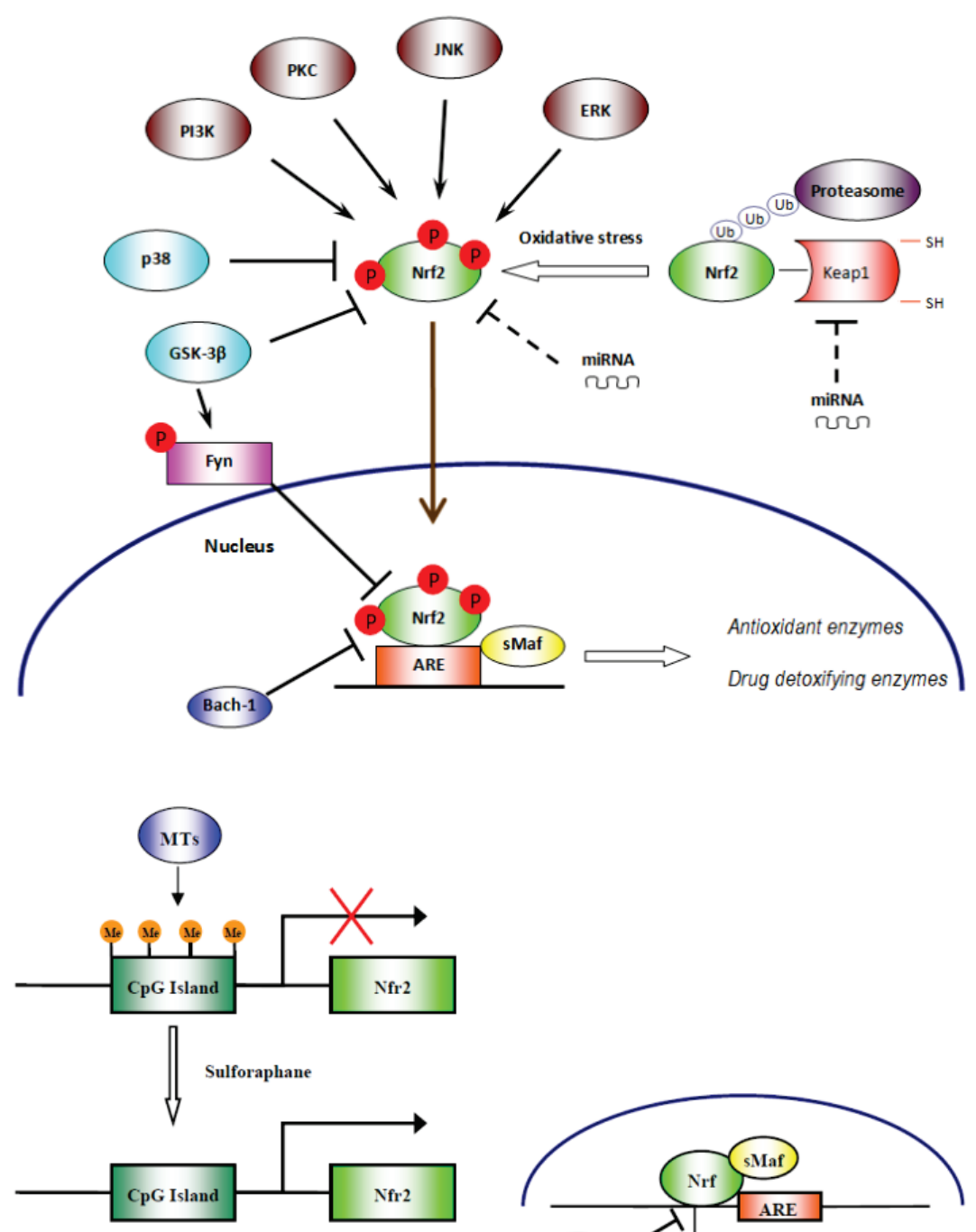

Fig. 1. Regulation of Nrf2 by kinases. Under normal or unstressed conditions, Nrf2 is kept in the cytoplasm by Keap1 (Kelch-like $\mathrm{ECH}$-associated protein 1) which promotes Nrf2 degradation by ubiquitination. Ubiquitinated (Ub) Nrf2 is transported to the proteasome, where it is degraded and its components recycled. Oxidative stress disrupts critical cysteine residues in Keap1, disrupting the Keap1 ubiquitination system. When Nrf2 is not ubiquitinated translocates into the nucleus. In the nucleus forms a heterodimer with a small Maf protein and binds to the antioxidant response element (ARE) in the upstream promoter region of many antioxidative genes, and initiates their transcription. Kinases PI3K (phosphatidylinositol-3-kinase), PKC (protein kinase $\mathrm{C}$ ), JNK (c-Jun $\mathrm{NH} 2$-terminal protein kinase) and ERK (extracellular signalregulated kinase) activate Nrf2 by its phosphorylation. p38-MAPK and GSK-3 $\beta$ (glycogen synthase kinase-3 $\beta$ ) inhibit Nrf2 activation.

Fig. 2. Epigenetic regulation of Nrf2 gene. Methylation the CpG islands in promoter region of Nrf2 by metyltransferases (MTs) blocks transcription of the Nrf2 gene. Nrf2 deacetylation in the nucleus by histone deacetylases (HDACs) promotes its release from antioxidant response element (ARE) and nuclear export. Sulforaphane blocks MTs and HDACs expression and thereby activates Nrf2 mediated gene expression. 
Nrf2 is also regulated through epigenetic. This regulation has been studied in several studies ( $\mathrm{Yu}$ et al. 2010, Zhang et al. 2013, Su et al. 2014). CpG islands that take part on epigenetic regulation of $\mathrm{Nrf} 2$ were discovered in promotor region of $\mathrm{Nrf2}$ (Yu et al. 2010). Methylation of these islands in promoter region by methyltransferases (MTs) blocks its transcription (Fig. 2). MTs increase hypermethylation of $\mathrm{CpG}$ islands in $\mathrm{Nrf2}$ promotors. Nrf2 deacetylation in the nucleus is provided by histone deacetylases (HDACs). Sulforaphane acts in epigenetic regulation of $\mathrm{Nrf} 2$ by demethylation of $\mathrm{CpG}$ islands. Methylation the $\mathrm{CpG}$ islands in promoter region of Nrf2 by MTs blocks transcription of the Nrf2 gene. It seems that sulforaphane can participate on epigenetic regulation of $\mathrm{Nrf} 2$ by demethylation of $\mathrm{GpC}$ islands (Su et al. 2014). This demethylation leads to increased expression of Nrf2-induced antioxidant and detoxificant genes (Fig. 2). Another way of epigenetic regulation is Nrf2 deacetylation in the nucleus by HDACs that promote its release from antioxidant response element (ARE) and nuclear export (Zhang et al. 2013, Su et al. 2014). Sulforaphane action is realized not only through blockings of DNA methylation by MTs but also through blocking of HDACs expression that lead to Nrf2-ARE activation and $\mathrm{Nrf2}$-mediated gene expression.

\section{Nrf2 and hypertension}

The mechanistic role of Nrf2 expression in blood pressure regulation is still not fully elucidated, however several correlations have been found among Nrf2 and ROS in vessels and heart in hypertension animal models (Silva-Palacios et al. 2016). Dysregulation of ROS sources (NOX, uncoupling NOS, ETC) during hypertension results in increased ROS generation and oxidative stress. It is not clear if oxidative stress is a contributing factor to hypertension or if hypertension induces oxidative stress (Howden 2013). Nrf2 may also be important in blood pressure regulation in many ways. One of possible mechanism is by induction heme oxygenase-1 (HO-1) gene expression, which overexpression can lower blood pressure in model of spontaneously hypertensive rats (SHR) (Chen et al. 2013). HO-1 is a cytoprotective enzyme that degrades heme to generate carbon monoxide (CO), biliverdin, and iron. $\mathrm{CO}$ is able to regulate vascular response by inhibition of vasoconstrictor, endothelin and/or by activating soluble guanylate cyclase and producing cGMP, which has vasodilatory effects (Chen et al. 2003). Biliverdin can be converted to the potent antioxidant bilirubin, and both can directly inhibit NOX activity and thereby contribute to the actions of HO-1 to sustain vascular homeostasis (Datla et al. 2007). In SHR model of hypertension Nrf2 and Nrf2-regulated antioxidant enzymes are downregulated, which contribute to reduced antioxidant capacity, increased oxidative stress and vascular dysfunction. These findings can be explained by increased expression of Bach 1 (Nrf2 corepressor) after AngII-induced stimulation. Sulforaphane, the $\mathrm{Nrf2}$ activator, ameliorates the redox imbalance observed in the vasculature of SHR (Lopes et al. 2015). Diet containing sulforaphane precursor decreased vascular oxidative stress, improved endothelial-dependent vasodilatation and lower blood pressure (Wu et al. 2004). Another study documented that long-term administration of another Nrf2 activator, resveratrol, reduced oxidative stress and attenuated severity and progression of hypertension in SHR (Javkhedkar et al. 2015).

$\mathrm{Nrf2}$ may be vasoprotective in hypertension. On the other hand, there is evidence for a dual role of $\mathrm{Nrf} 2$ in other cardiovascular diseases. Nrf2 activation is cardioprotective when myocardial autophagy function is sufficient. Autophagy impairment switches off Jak2/Fyn signaling for Nrf2 export and degradation. Nuclear accumulation of $\mathrm{Nrf2}$ upregulates angiotensinogen expression, and thereby enhances AngII signaling contributing to cardiac dysfunction (Qin et al. 2016).

\section{Nrf2 and cardiac hypertrophy}

Cardiac hypertrophy is a common pathological feature in the natural course of some major cardiovascular diseases, including hypertension. Furthermore, cardiac hypertrophy is strongly associated with an increased risk of heart failure and sudden cardiac death. Important role in pathophysiology of cardiac hypertrophy plays changes in redox balance (Giordano 2005). Recent study demonstrated that knock out of Nrf2 in mice is linked to cardiac hypertrophy (Erkens et al. 2015). Nrf2 deficient mice had a left ventricular cardiac hypertrophy, left ventricular diastolic dysfunction, and impaired $\mathrm{Ca}^{2+}$ homeostasis. Interesting was the finding that vascular function in these animals was fully preserved via compensatory upregulation of eNOS. It has been suggested that this eNOS upregulation may represent a way to compensate detrimental changes in vascular tissues due to dysregulation of redox control and chronic adaptation to the lack of Nrf2.

Several studies revealed the role of Nrf2 in AngII-induced oxidative stress and the subsequent 
hypertrophic remodeling of the heart (Li et al. 2011, Hybertson et al. 2011). Nrf2 has also been identified as a promising therapeutic target against AngII-mediated cardiac hypertrophy and heart failure (Hybertson et al. 2011). Data suggest that to the Nrf2-mediated protection against angiotensin II induced cardiac hypertrophy in cultured cardiomyocytes contribute up-regulation of p27(kip1) (Li et al. 2011).

The important role of $\mathrm{Nrf} 2$ in cardiac hypertrophy show data obtained in a mouse hypoxic model of pulmonary hypertension characterized also by right ventricular hypertrophy (MacRitchie et al. 2016). Administration of the potent sphingosine kinase 1 inhibitor, PF-543, reduced right ventricular hypertrophy and these effects were connected with an increase in the expression of Nrf2. Moreover, a significant reduction in cardiomyocyte death and $\mathrm{p} 53$ protein has been found. The data suggest that $\mathrm{Nrf} 2$ is potentially a key molecule in preserving right ventricular function and may be up-regulated in an attempt to limit damage to the right ventricle. Nrf2 was also found to mediate the cardioprotective effects of sodium sulfide $\left(\mathrm{Na}_{2} \mathrm{~S}\right)$ therapy in the setting of heart failure (Shimizu et al. 2016). $\mathrm{Na}_{2} \mathrm{~S}$ attenuated the ischemic-induced heart failure by enhancing proteasomal function in an Nrf2-dependent manner. The effects of sodium sulfide were connected with enhanced Nrf2 signaling, improved left ventricular function, and less cardiac hypertrophy after the induction of heart failure. Moreover, the protection failed in Nrf2 deficient mice.

\section{Nrf2 and cardiomyopathies}

Oxidative damage of the myocardium and vasculature leads to pathologic alterations associated with diabetic cardiovascular complications. Hyperglycemia, glucose autoxidation, accumulation of advanced glycosylation end products (AGEs), and angiotensin II receptor type 1, promote increased ROS and RNS production in diabetic vessels and myocardium (Jay et al. 2006). This increased ROS/RNS production is a risk factor for diabetic cardiomyopathy. The negative impact of prolonged oxidative stress in diabetic hearts is associated with impaired antioxidant defense system, inactivation of antioxidant enzymes, depletion of endogenous antioxidants and promoting deregulation of redox-dependent transcription factors like Nrf2 (Rajesh et al. 2010). It has been shown significant down-regulation of cardiac Nrf2 expression in diabetic animals and patients (Tan et al. 2011). To the importance of Nrf2 in diabetes point data obtained in a type 1 diabetic mice model showing that low-dose radiation prevented diabetic cardiomyopathy by improving cardiac function and hypertrophic remodeling and these cardioprotective effects were attributed to Akt/Nrf2-mediated anti-oxidant pathway (Zhang et al. 2016). Under diabetic conditions Akt activation and $\mathrm{Nrf2}$ expression was decreased and this was associated with cardiac damage. Nrf2 system has been proposed to prevent onset of diabetes mellitus and to play an important role in maintaining glucose metabolism through the regulation of insulin secretion and glucose utilization, as well as by regulating lipid metabolism (Uruno et al. 2013, 2015).

Nrf2 pathway has been shown to play an important role also in cardiac remodeling induced by anticancer drugs. Anthracycline anticancer drugs such as doxorubicin (DOX) can induce cardiotoxicity and heart failure, and crucial role in realization of their toxic effects play oxidative stress and mitochondrial damage. We recently reported that chronic application of DOX induced cardiotoxic effects mediated by increased production of ROS, reduction of superoxide dismutase (SOD) protein levels and activities, as well as apoptosis induction (Barteková et al. 2015). Recent study demonstrated the effects of Nrf2 activator sulforaphane on cardiotoxic effects induced by DOX in mice (Singh et al. 2015). Sulforaphane restored cardiac function after DOX treatment and induced a significant reduction of DOX-induced cardiomyopathy and mortality. Protection of cardiac H9c2 cells from doxorubicin-induced cytotoxicity was also mediated through the Keap1/Nrf2 signaling pathway which countered the cardiac damage. The function of $\mathrm{Nrf2}$ as an endogenous suppressor of DOX-induced cardiotoxicity was confirmed in mice treated with a single intraperitoneal injection of DOX. The induction of cardiomyocyte necrosis and cardiac dysfunction was associated with oxidative stress, impaired autophagy, and accumulated polyubiquitinated protein aggregates. All these DOX-induced negative effects on cardiac function were exaggerated in Nrf2 knockout (Nrf2(-/-)) mice (Li et al. 2014).

\section{The role of Nrf2 in cardioprotection against myocardial ischemia/reperfusion injury}

Ischemia and reperfusion ( $\mathrm{I} / \mathrm{R})$ injury is a major cause of morbidity and mortality after cardiac operations and myocardial infarctions. $\mathrm{I} / \mathrm{R}$ injury is strongly associated with mitochondrial dysfunction and increased oxidative stress. I/R-induced oxidative stress in turn 
influences signaling pathways that contribute to apoptosis, stress of endoplasmic reticulum, altered cell migration and proliferation (Giordano 2005). The Nrf2/ARE pathway affects cell survival through a variety of mediators, including apoptotic proteins such as Bcl-2 and Bax (Das et al. 2012) and phase II enzymes such as HO-1, a stress protein which is regarded as a sensitive and reliable indicator of cellular oxidative stress (Kim et al. 2011). Ischemia/reperfusion enhances Nrf2 dissociation from Keap1, thus facilitating Nrf2 translocation to the nucleus, binding to the ARE, and activation of phase II detoxifying and antioxidant genes (Shah et al. 2007). Nrf2 is an important factor in controlling both constitutive and inducible expression of a wide spectrum of antioxidants and phase II enzymes in cardiac cells and is responsible for protecting these cells against oxidative stress. This is supported by findings that Nrf2 is involved in protection of cardiac fibroblasts and cardiomyocytes against oxidative stress by increasing detoxification pathways and antioxidant potentials (Zhu et al. 2005, Purdom-Dickinson et al. 2007). To the important role of $\mathrm{Nrf} 2$ in myocardial responses to ischemia/reperfusion point data showing increased sensitivity to ischemic injury in Nrf2 deficient mice (Xu et al. 2014). This study also documented that Nrf2 may also be implicated in the cardioprotection offered by ischemic preconditioning (IP). IP induced an elevation of Nrf2 protein levels and this correlated well with IP-mediated cardioprotection.

Deng et al. (2013) demonstrated positive effects of $\alpha$-lipoic acid on reduction of infarct size and preservation of cardiac function after ischemia/ reperfusion in rat which was related to the activation of the Nrf2 pathway (Deng et al. 2013). This stimulation of Nrf2 during cardioprotection was connected with an activation of pro-survival PI3K/Akt kinase pathway which was shown to play a role in mechanisms of increased myocardial tolerance to ischemia/reperfusion injury (Griecsova et al. 2015) and reduction of oxidative stress (Xu and Liu 2013). Results of recent study showed that resveratrol exerted significant antioxidant and cardioprotective effects following myocardial ischemia through the activation of Nrf2/ARE pathway connected with an enhanced levels of both Nrf2 and heme oxygenase-1 (Cheng et al. 2015). Resveratrol also markedly enhanced the activities of antioxidant enzymes SOD and glutathione peroxidase (GSH-PX), and reduced the level of malondialdehyde in rats exposed to ischemia/reperfusion. In another study was documented the role of $\mathrm{Nrf} 2$ signaling in cardioprotection against myocardial ischemia/reperfusion injury induced by plumbagin. The regulation of redox imbalance induced by $\mathrm{I} / \mathrm{R}$ injury was connected with modulation of $\mathrm{Nrf} 2$ (Wang et al. 2016). Another study showed attenuation of myocardial I/R injury by atorvastatin and suggested was the association of atorvastatin activity with the $\mathrm{Nrf} 2$ activation (Sun et al. 2015). Atorvastatin attenuated inflammation and oxidative stress induced by $\mathrm{I} / \mathrm{R}$ injury by activating the expression of $\mathrm{Nrf} 2$, which in turn upregulated HO-1 expression. Atorvastatin was effective in stimulating the activities of SOD and GSH-PX, and the data suggested that atorvastatin protected against $\mathrm{I} / \mathrm{R}$ injury also through the reduction of oxidative stress.

\section{Conclusions}

Nuclear transcription factor Nrf2 plays a key role in orchestrating cellular antioxidant defenses and in maintaining redox homeostasis. Nrf2 is a critical component involved in induction of antioxidative and other cytoprotective genes which provide protection against oxidative stress induced damage in a variety of cardiovascular diseases. Taken together, the results of several studies show that Nrf2 activation may play a key role in cardioprotection and dysregulation of Nrf2 activity is causally associated with susceptibility to disease. Current information indicates that Nrf2 pathway could be promising target for prevention and treatment of cardiovascular diseases, in which oxidative stress is an important partner. However, it is essential to understand the details of the regulation of $\mathrm{Nrf} 2$ and of the precise mechanisms by which it affects myocardial function at pathological conditions.

\section{Conflict of Interest}

There is no conflict of interest.

\section{Acknowledgements}

This study was supported by grants VEGA SR no. 2/0061/16, 2/0108/15, 2/0129/14 and APVV-0348-12.

\footnotetext{
Abbreviations

AGEs, advanced glycosylation end products; AngII, angiotensin II; ARE, antioxidant response element; ATP, adenosine triphosphate; AT1R, angiotensin II receptor type 1; CO, carbon monoxide; cGMP, cyclic guanosine monophosphate; $\mathrm{CpG}$ islands, cytosine being 5 prime to the guanine base, short interspersed DNA sequences GC and CpG-rich; CVD, cardiovascular diseases; DOX,
} 
doxorubicin; eNOS, endothelial nitric oxide synthase; ERK, extracellular signal-regulated kinase; ETC, electron transport chain; GSH-PX, glutathione peroxidase; GSK-3 $\beta$, glycogen synthase kinase-3 $\beta$; HDACs, histone deacetylases; HO-1, heme oxygenase-1; IP, ischemic preconditioning; I/R, ischemia and reperfusion; JNK, c-Jun NH2-terminal protein kinase; Keap1, Kelch-like ECH-associated protein 1; MAPKs, mitogen-activated protein kinases; miRNA, micro-ribonucleic acid; $\mathrm{Na}_{2} \mathrm{~S}$, sodium sulfide; MnSOD, manganese superoxide dismutase; NOS, nitric oxide synthase; MTs, methyltransferases; NOX, NADPH oxidase; NO, nitric oxide; Nrf2, nuclear factor erythroid 2-related factor; $\mathrm{ONOO}^{-}$, peroxynitrite; PI3K, phosphatidylinositol-3kinase; $\mathrm{PKC}$, protein kinase $\mathrm{C}$; ROS, reactive oxygen species; RNS, reactive nitrogen species; SHR, spontaneously hypertensive rats; SOD, superoxide dismutase; XO, xanthine oxidase.

\section{References}

BARTEKOVÁ M, ŠIMONČÍKOVÁ P, FOGARASSYOVÁ M, IVANOVÁ M, OKRUHLICOVÁ L', TRIBULOVÁ N, DOVINOVÁ I, BARANČÍK M: Quercetin improves postischemic recovery of heart function in doxorubicintreated rats and prevents doxorubicin-induced matrix metalloproteinase-2 activation and apoptosis induction. Int J Mol Sci 16: 8168-8185, 2015.

BUENDIA I, MICHALSKA P, NAVARRO E, GAMEIRO I, EGEA J, LEÓN R: Nrf2-ARE pathway: an emerging target against oxidative stress and neuroinflammation in neurodegenerative diseases. Pharmacol Ther 157: 84-104, 2016.

CALABRESE V, CORNELIUS C, DINKOVA-KOSTOVA AT, CALABRESE EJ, MATTSON MP: Cellular stress responses, the hormesis paradigm, and vitagenes: novel targets for therapeutic intervention in neurodegenerative disorders. Antioxid Redox Signal 13: 1763-1811, 2010.

CALABRESE V, CORNELIUS C, DINKOVA-KOSTOVA AT, IAVICOLI I, Di PAOLA R, KOVERECH A, CUZZOCREA S, ENRICO RIZZARELLI E, CALABRESE EJ: Cellular stress responses, hormetic phytochemicals and vitagenes in aging and longevity. Biochim Biophys Acta 1822: 753-783, 2012.

CARMONA-RAMÍREZ I, SANTAMARÍA A, TOBÓN-VELASCO JC, OROZCO-IBARRA M, GONZÁLEZHERRERA IG, PEDRAZA-CHAVERRÍ J, MALDONADO PD: Curcumin restores Nrf2 levels and prevents quinolinic acid-induced neurotoxicity $J$ Nutr Biochem 24: 14-24, 2013.

CHEN TM, LI J, LIU L, FAN L, LI XY, WANG YT, ABRAHAM NG, CAO J: Effects of heme oxygenase-1 upregulation on blood pressure and cardiac function in an animal model of hypertensive myocardial infarction. Int J Mol Sci 14: 2684-2706, 2013.

CHEN YH, YET SF, PERRELLA MA: Role of heme oxygenase-1 in the regulation of blood pressure and cardiac function. Exp Biol Med (Maywood) 228: 447-453, 2003.

CHENG L, JIN Z, ZHAO R, REN K, DENG C, YU S: Resveratrol attenuates inflammation and oxidative stress induced by myocardial ischemia-reperfusion injury: role of Nrf2/ARE pathway. Int J Clin Exp Med 8: 1042010428, 2015.

CORNELIUS C, GRAZIANO A, CALABRESE EJ, CALABRESE V: Hormesis and vitagenes in aging and longevity: mitochondrial control and hormonal regulation. Horm Mol Biol Clin Investig 16: 73-89, 2013.

DAS A, GOPALAKRISHNAN B, VOSS OH, DOSEFF AI, VILLAMENA FA: Inhibition of ROS-induced apoptosis in endothelial cells by nitrone spin traps via induction of phase II enzymes and suppression of mitochondriadependent pro-apoptotic signaling. Biochem Pharmacol 84: 486-497, 2012.

DATLA SR, DUSTING GJ, MORI TA, TAYLOR CJ, CROFT KD, JIANG F: Induction of heme oxygenase-1 in vivo suppresses NADPH oxidase derived oxidative stress. Hypertension 50: 636-642, 2007.

DATTILO S, MANCUSO C, KOVERECH G, Di MAURO P, ONTARIO ML, PETRALIA CC, PETRALIA A, MAIOLINO L, SERRA A, CALABRESE EJ, CALABRESE V: Heat shock proteins and hormesis in the diagnosis and treatment of neurodegenerative diseases. Immun Ageing 12: 20, 2015.

DENG C, SUN Z, TONG G, YI W, MA L, ZHAO B, CAO F, YI D: $\alpha$-Lipoic acid reduces infarct size and preserves cardiac function in rat myocardial ischemia/reperfusion injury through activation of PI3K/Akt/Nrf2 pathway. PLoS One 8: e58371, 2013.

DIKALOV S: Cross talk between mitochondria and NADPH oxidases. Free Radic Biol Med 51: 1289-1301, 2011. 
DIKALOV SI, UNGVARI Z: Role of mitochondrial oxidative stress in hypertension. Am J Physiol Heart Circ Physiol 305: H1417-H1427, 2013.

DIKALOV SI, NAZAREWICZ RR, BIKINEYEVA A, HILENSKI L, LASSÈGUE B, GRIENDLING KK, HARRISON DG, DIKALOVA AE: Nox2-induced production of mitochondrial superoxide in angiotensin IImediated endothelial oxidative stress and hypertension. Antioxid Redox Signal 20: 281-294, 2014.

DIKALOVA AE, BIKINEYEVA AT, BUDZYN K, NAZAREWICZ RR, MCCANN L, LEWIS W, HARRISON DG, DIKALOV SI: Therapeutic targeting of mitochondrial superoxide in hypertension. Circ Res 107: 106-116, 2010.

DOUGHAN AK, HARRISON DG, DIKALOV SI: Molecular mechanisms of angiotensin II-mediated mitochondrial dysfunction: linking mitochondrial oxidative damage and vascular endothelial dysfunction. Circ Res 102: 488-496, 2008.

ERKENS R, KRAMER CM, LÜCKSTÄDT W, PANKNIN C, KRAUSE L, WEIDENBACH M, DIRZKA J, KRENZ T, MERGIA E, SUVORAVA T, KELM M, CORTESE-KROTT MM: Left ventricular diastolic dysfunction in Nrf2 knock out mice is associated with cardiac hypertrophy, decreased expression of SERCA2a, and preserved endothelial function. Free Radic Biol Med 89: 906-917, 2015.

GIORDANO FJ: Oxygen, oxidative stress, hypoxia, and heart failure. J Clin Invest 115: 500-508, 2005.

GRIECSOVÁ L, FARKAŠOVÁ V, GÁBLOVSKÝ I, KHANDELWAL VK, BERNÁTOVÁ I, TATARKOVÁ Z, KAPLAN P, RAVINGEROVÁ T: Effect of maturation on the resistance of rat hearts against ischemia. Study of potential molecular mechanisms. Physiol Res 64 (Suppl 5): S685-S696, 2015.

HARRISON DG, CHEN W, DIKALIOV S, LI L: Regulation of endothelial cell tetrahydrobiopterin pathophysiological and therapeutic implications. Adv Pharmacol 60: 107-132, 2010.

HOWDEN R: Nrf2 and cardiovascular defense. Oxid Med Cell Longev 2013: 104308, 2013.

HUANG Y, LI W, SU Z, KONG AN: The complexity of the Nrf2 pathway: beyond the antioxidant response. $J$ Nutritional Biochem 26: 1401-1413, 2015.

HYBERTSON BM, GAO B, BOSE SK, MCCORD JM: Oxidative stress in health and disease: the therapeutic potential of Nrf2 activation. Mol Aspects Med 32: 234-246, 2011.

JAIN AK, JAISWAL AK: GSK-3beta acts upstream of Fyn kinase in regulation of nuclear export and degradation of NF-E2 related factor 2. J Biol Chem 282: 16502-16510, 2007.

JAVKHEDKAR AA, QUIROZ Y, RODRIGUEZ-ITURBE B, VAZIRI ND, LOKHANDWALA MF, BANDAY AA: Resveratrol restored Nrf2 function, reduced renal inflammation, and mitigated hypertension in spontaneously hypertensive rats. Am J Physiol Regul Integr Comp Physiol 308: R840-R846, 2015.

JAY D, HITOMI H, GRIENDLING KK: Oxidative stress and diabetic cardiovascular complications. Free Radic Biol Med 40: 183-192, 2006.

KANG KW, LEE SJ, PARK JW, KIM SG: Phosphatidylinositol 3-kinase regulates nuclear translocation of NF-E2related factor 2 through actin rearrangement in response to oxidative stress. Mol Pharmacol 62: 1001-1010, 2002.

KANNAN S, MUTHUSAMY VR, WHITEHEAD KJ, WANG L, GOMES AV, LITWIN SE, KENSLER TW, ABEL ED, HOIDAL JR, RAJASEKARAN NS: Nrf2 deficiency prevents reductive stress-induced hypertrophic cardiomyopathy. Cardiovasc Res 100: 63-73, 2013.

LI J, ZHANG C, XING Y, JANICKI JS, YAMAMOTO M, WANG XL, TANG DQ, CUI T: Up-regulation of p27(kip1) contributes to Nrf2-mediated protection against angiotensin II induced cardiac hypertrophy. Cardiovasc Res 90: 315-324, 2011.

LI S, WANG W, NIU T, WANG H, LI B, SHAO L, LAI Y, LI H, JANICKI JS, WANG XL, TANG D, CUI T: Nrf2 deficiency exaggerates doxorubicin-induced cardiotoxicity and cardiac dysfunction. Oxid Med Cell Longev 2014: 748524, 2014.

LOPES RA, NEVES KB, TOSTES RC, MONTEZANO AC, TOUYZ RM: Downregulation of nuclear factor erythroid 2-related factor and associated antioxidant genes contributes to redox-sensitive vascular dysfunction in hypertension. Hypertension 66: 1240-1250, 2015. 
MACRITCHIE N, VOLPERT G, AL WASHIH M, WATSON DG, FUTERMAN AH, KENNEDY S, PYNE S, PYNE $\mathrm{NJ}$ : Effect of the sphingosine kinase 1 selective inhibitor, PF-543 on arterial and cardiac remodelling in a hypoxic model of pulmonary arterial hypertension. Cell Signal 28: 946-955, 2016.

MAJZUNOVA M, DOVINOVA I, BARANCIK M, CHAN JY: Redox signaling in pathophysiology of hypertension. J Biomed Sci 20: 69, 2013.

MONTEZANO AC, TSIROPOULOU S, DULAK-LIS M, HARVEY A, CAMARGO L DE L, TOUYZ RM: Redox signaling, Nox5 and vascular remodeling in hypertension. Curr Opin Nephrol Hypertens 24: 425-433, 2015.

MORITA T, KOUREMBANAS S: Endothelial cell expression of vasoconstrictors and growth factors is regulated by smooth muscle cell-derived carbon monoxide. J Clin Invest 96: 2676-2682, 1995.

NARASIMHAN M, PATEL D, VEDPATHAK D, RATHINAM M, HENDERSON G, MAHIMAINATHAN L: Identification of novel microRNAs in post-transcriptional control of Nrf2 expression and redox homeostasis in neuronal, SH-SY5Y cells. PloS One 7: e51111, 2012.

NARASIMHAN M, HONG J, ATIENO N, MUTHUSAMY VR, DAVIDSON CJ, ABU-RMAILEH N, RICHARDSON RS, GOMES AV, HOIDAL JR, RAJASEKARAN NS: Nrf2 deficiency promotes apoptosis and impairs PAX7/MyoD expression in aging skeletal muscle cells. Free Radic Biol Med 71: 402-414, 2014.

NUMAZAWA S, ISHIKAWA M, YOSHIDA A, TANAKA S, YOSHIDA T: Atypical protein kinase C mediates activation of NF-E2-related factor 2 in response to oxidative stress. Am J Physiol Cell Physiol 285: C334C342, 2003.

PAPP D, LENTI K, MÓDOS D, FAZEKAS D, DÚL Z, TÜREI D, FÖLDVÁRI-NAGY L, NUSSINOV R, CSERMELY P, KORCSMÁROS T: The NRF2-related interactome and regulome contain multifunctional proteins and fine-tuned autoregulatory loops. FEBS Lett 586: 1795-1802, 2012.

PURDOM-DICKINSON SE, LIN Y, DEDEK M, MORRISSY S, JOHNSON J, CHEN QM: Induction of antioxidant and detoxification response by oxidants in cardiomyocytes: evidence from gene expression profiling and activation of Nrf2 transcription factor. J Mol Cell Cardiol 42: 159-176, 2007.

QIN Q, QU C, NIU T, ZANG H, QI L, LYU L, WANG X, NAGARKATTI M, NAGARKATTI P, JANICKI JS, WANG XL, CUI T: Nrf2-mediated cardiac maladaptive remodeling and dysfunction in a setting of autophagy insufficiency. Hypertension 67: 107-117, 2016.

RADA P, ROJO AI, CHOWDHRY S, MCMAHON M, HAYES JD, CUADRADO A: SCF/\{beta $\}$-TrCP promotes glycogen synthase kinase 3-dependent degradation of the Nrf2 transcription factor in a Keap1-independent manner. Mol Cell Biol 31: 1121-1133, 2011.

RAJESH M, MUKHOPADHYAY P, BÁTKAI S, PATEL V, SAITO K, MATSUMOTO S, KASHIWAYA Y, HORVÁTH B, MUKHOPADHYAY B, BECKER L, HASKÓ G, LIAUDET L, WINK DA, VEVES A, MECHOULAM R, PACHER P: Cannabidiol attenuates cardiac dysfunction, oxidative stress, fibrosis, and inflammatory and cell death signaling pathways in diabetic cardiomyopathy. J Am Coll Cardiol 56: 2115-2125, 2010.

SHAH ZA, LI RC, THIMMULAPPA RK, KENSLER TW, YAMAMOTO M, BISWAL S, DORÉ S: Role of reactive oxygen species in modulation of Nrf2 following ischemic reperfusion injury. Neuroscience 147: 53-59, 2007.

SHIMIZU Y, NICHOLSON CK, LAMBERT JP, BARR LA, KUEK N, HERSZENHAUT D, TAN L, MUROHARA T, HANSEN JM, HUSAIN A, NAQVI N, CALVERT JW: Sodium sulfide attenuates ischemic-induced heart failure by enhancing proteasomal function in an Nrf2-dependent manner. Circ Heart Fail 9: e002368, 2016.

SILVA-PALACIOS A, KÖNIGSBERG M, ZAZUETA C: Nrf2 signaling and redox homeostasis in the aging heart: a potential target to prevent cardiovascular diseases? Ageing Res Rev 26: 81-95, 2016.

SINGH P, SHARMA R, MCELHANON K, ALLEN CD, MEGYESI JK, BENEŠ H, SINGH SP: Sulforaphane protects the heart from doxorubicin-induced toxicity. Free Radic Biol Med 86: 90-101, 2015.

SU ZY, ZHANG C, LEE JH, SHU L, WU TY, KHOR TO, CONNEY AH, LU YP, KONG AN: Requirement and epigenetics reprogramming of $\mathrm{Nrf2}$ in suppression of tumor promoter TPA-induced mouse skin cell transformation by sulforaphane. Cancer Prev Res (Phila) 7: 319-329, 2014.

SUN G, LI Y, JI Z: Atorvastatin attenuates inflammation and oxidative stress induced by ischemia/reperfusion in rat heart via the Nrf2 transcription factor. Int J Clin Exp Med 8: 14837-14845, 2015. 
SUN J, BRAND M, ZENKE Y, TASHIRO S, GROUDINE M, IGARASHI K: Heme regulates the dynamic exchange of Bach1 and NF-E2-related factors in the Maf transcription factor network. Proc Natl Acad Sci USA 101: 1461-1466, 2004.

SUN Z, HUANG Z, ZHANG DD: Phosphorylation of Nrf2 at multiple sites by MAP kinases has a limited contribution in modulating the Nrf2-dependent antioxidant response. PLoS One 4: e6588, 2009.

TAN Y, ICHIKAWA T, LI J, SI Q, YANG H, CHEN X, GOLDBLATT CS, MEYER CJ, LI X, CAI L, CUI T: Diabetic downregulation of Nrf2 activity via ERK contributes to oxidative stress-induced insulin resistance in cardiac cells in vitro and in vivo. Diabetes 60: 625-633, 2011.

TRIBULOVA N, EGAN BENOVA T, SZEIFFOVA BACOVA B, VICZENCZOVA C, BARANCIK M: New aspects of pathogenesis of atrial fibrillation: remodelling of intercalated discs. J Physiol Pharmacol 66: 625-634, 2015.

URUNO A, FURUSAWA Y, YAGISHITA Y, FUKUTOMI T, MURAMATSU H, NEGISHI T, SUGAWARA A, KENSLER TW, YAMAMOTO M: The Keap1-Nrf2 system prevents onset of diabetes mellitus. Mol Cell Biol 33: 2996-3010, 2013.

URUNO A, YAGISHITA Y, YAMAMOTO M: The Keap1-Nrf2 system and diabetes mellitus. Arch Biochem Biophys 566: 76-84, 2015.

WANG SX, WANG J, SHAO JB, TANG WN, ZHONG JQ: Plumbagin mediates cardioprotection against myocardial ischemia/reperfusion injury through Nrf-2 signaling. Med Sci Monit 22: 1250-1257, 2016.

WIDDER JD, FRACCAROLLO D, GALUPPO P, HANSEN JM, JONES DP, ERTL G, BAUERSACHS J: Attenuation of angiotensin II-induced vascular dysfunction and hypertension by overexpression of Thioredoxin 2 . Hypertension 54: 338-344, 2009.

WU L, NOYAN ASHRAF MH, FACCI M, WANG R, PATERSON PG, FERRIE A, JUURLINK BH: Dietary approach to attenuate oxidative stress, hypertension, and inflammation in the cardiovascular system. Proc Natl Acad Sci USA 101: 7094-7099, 2004.

XU L, LIU Y: Administration of telmisartan reduced systolic blood pressure and oxidative stress probably through the activation of PI3K/Akt/eNOS pathway and NO release in spontaneously hypertensive rats. Physiol Res 62 : 351-359, 2013.

XU B, ZHANG J, STROM J, LEE S, CHEN QM: Myocardial ischemic reperfusion induces de novo Nrf2 protein translation. Biochim Biophys Acta 1842: 1638-1647, 2014.

YU S, KHOR TO, CHEUNG KL, LI W, WU TY, HUANG Y, FOSTER BA, KAN YW, KONG AN: Nrf2 expression is regulated by epigenetic mechanisms in prostate cancer of TRAMP mice. PLoS One 5: e8579, 2010.

ZHANG C, SU ZY, KHOR TO, SHU L, KONG AN: Sulforaphane enhances Nrf2 expression in prostate cancer TRAMP C1 cells through epigenetic regulation. Biochem Pharmacol 85: 1398-1404, 2013.

ZHANG C, SHU L, KONG AT: MicroRNAs: new players in cancer prevention targeting Nrf2, oxidative stress and inflammatory pathways. Curr Pharmacol Rep 1: 21-30, 2015.

ZHANG F, LIN X, YU L, LI W, QIAN D, CHENG P, HE L, YANG H, CAI L, ZHANG C: Low-dose radiation prevents type 1 diabetes-induced cardiomyopathy via activation of AKT mediated anti-apoptotic and antioxidant effects. J Cell Mol Med 20: 1352-1366, 2016.

ZHU H, ITOH K, YAMAMOTO M, ZWEIER JL, LI Y: Role of Nrf2 signaling in regulation of antioxidants and phase 2 enzymes in cardiac fibroblasts: protection against reactive oxygen and nitrogen species-induced cell injury. FEBS Lett 579: 3029-3036, 2005. 